\title{
Confirmation of Plasmodium falciparum in vitro resistance to monodesethylamodiaquine and chloroquine in Dakar, Senegal, in 2015
}

\author{
Silman Diawara' ${ }^{1}$, Marylin Madamett ${ }^{2,3,4}$, Mame Bou Kounta ${ }^{5}$, Gora Lo ${ }^{6,7}$, Khalifa Ababacar Wade ${ }^{5}$, \\ Aminata Nakoulima ${ }^{8}$, Raymond Bercion ${ }^{9}$, Rémy Amalvict ${ }^{2,3,4}$, Mamadou Wague Gueye ${ }^{1}$, Bécaye Fall ${ }^{1}$, \\ Bakary Diatta ${ }^{10}$ and Bruno Pradines ${\text { s, } 2,3,4^{*}}^{2}$
}

\begin{abstract}
Background: In response to increasing resistance to anti-malarial drugs, Senegal adopted artemisinin-based combination therapy (ACT) as the first-line treatment for uncomplicated malaria in 2006. However, resistance of Plasmodium falciparum parasites to artemisinin derivatives, characterized by delayed parasite clearance after treatment with ACT or artesunate monotherapy, has recently emerged and rapidly spread in Southeast Asia. After 10 years of stability with rates ranging from 5.6 to $11.8 \%$, the prevalence of parasites with reduced susceptibility in vitro to monodesethylamodiaquine, the active metabolite of an ACT partner drug, increased to 30.6\% in 2014 in Dakar. Additionally, after a decrease of the in vitro chloroquine resistance in Dakar in 2009-2011, the prevalence of parasites that showed in vitro chloroquine resistance increased again to approximately 50\% in Dakar since 2013. The aim of this study was to follow the evolution of the susceptibility to ACT partners and other anti-malarial drugs in 2015 in Dakar. An in vitro test is the only method currently available to provide an early indication of resistance to ACT partners.

Results: Thirty-two P. falciparum isolates collected in 2015 in Dakar were analysed using a standard ex vivo assay based on an HRP2 ELISA. The prevalence of $P$. falciparum parasites with reduced susceptibility in vitro to monodesethylamodiaquine, chloroquine, mefloquine, doxycycline and quinine was 28.1, 46.9, 45.2, 31.2 and 9.7\%, respectively. None of the parasites were resistant to lumefantrine, piperaquine, pyronaridine, dihydroartemisinin and artesunate. These results confirm an increase in the reduced susceptibility to monodesethylamodiaquine observed in 2014 in Dakar and the chloroquine resistance observed in 2013. The in vitro resistance seems to be established in Dakar. Additionally, the prevalence of parasites with reduced susceptibility to doxycycline has increased two-fold compared to 2014.

Conclusions: The establishment of a reduced susceptibility to monodesethylamodiaquine as well as chloroquine resistance, and the emergence of a reduced susceptibility to doxycycline are disturbing. The in vitro and in vivo surveillance of anti-malarial drugs must be implemented in Senegal.
\end{abstract}

Keywords: Malaria, Plasmodium falciparum, Anti-malarial drug, In vitro, Resistance, Senegal

\section{Background}

In response to increasing resistance to anti-malarial drugs, Senegal adopted an artemisinin-based combination therapy $(\mathrm{ACT})$ as the first-line treatment for

\footnotetext{
*Correspondence: bruno.pradines@gmail.com

${ }^{4}$ Centre National de Référence du Paludisme, Marseille, France

Full list of author information is available at the end of the article
}

uncomplicated malaria in 2006 [1]. However, the resistance of Plasmodium falciparum parasites to artemisinin derivatives, characterized by delayed parasite clearance after treatment with ACT or artesunate monotherapy, has recently emerged and rapidly spread in Southeast Asia $[2,3]$. No evidence exists for the emergence of artemisinin resistance in Senegal. However, active surveillance of temporal trends in the ex vivo susceptibility to 
the anti-malarial drugs used as partner drugs in ACT, such as monodesethylamodiaquine, the active metabolite of amodiaquine (artesunate-amodiaquine), lumefantrine (artemether-lumefantrine), piperaquine (dihydroartemisinin-piperaquine) or pyronaridine (artesunatepyronaridine), is essential. After 10 years of stability with rates ranging from 5.6 to $11.8 \%$ [4-6], the prevalence of parasites with reduced susceptibility to monodesethylamodiaquine increased to $30.6 \%$ in 2014 in Dakar [7]. The prevalence of $P$. falciparum isolates with reduced susceptibility to lumefantrine remained low, below $3 \%$, until 2014 [4-7]. Additionally, after a decrease in the in vitro chloroquine resistance in Dakar in 2009-2011 that paralleled the withdrawal of chloroquine treatment $[4,5]$, the prevalence of parasites with in vitro chloroquine resistance increased again to approximately $50 \%$ in Dakar since 2013 [6, 7]. The emergence and re-emergence of parasites with in vitro resistance to monodesethylamodiaquine and chloroquine is disturbing.

The aim of this study was to follow the evolution of the susceptibility to ACT partners and to other anti-malarial drugs in 2015 in Dakar.

\section{Methods}

\section{Patients and sample collection}

Thirty-two P. falciparum isolates were collected from September to November 2015 and analysed using the standard in vitro assay based on HRP2 ELISA at the Hôpital Principal of Dakar. Nineteen isolates came from patients (59.4\%) who were recruited from the emergency unit. The remainder came from the Inter-armies Medical Centre of Dakar (21.9\%), the Institut Pasteur of Dakar and other departments of the Hôpital Principal of Dakar.

One of the 32 patients was not from Dakar or its districts. Two patients had travelled during the previous month (one in Senegal and one in Saudi Arabia).

Anti-malarial treatment prior to admission was not recorded. At the Inter-armies Medical Centre of Dakar and the Institut Pasteur of Dakar, the patients were diagnosed only and were not treated. At the Hôpital Principal of Dakar, the patients were treated with diverse treatment protocols (i) quinine (9.5\%), (ii) intra-venous artesunate followed by artemether-lumefantrine (4.8\%), (iii) intravenous artesunate in combination with doxycycline followed by artemether-lumefantrine-doxycycline (9.5\%), or (iv) intra-muscular artemether with doxycycline followed by artemether-lumefantrine-doxycycline (76.2\%). All of these patients were successfully cured.

Venous blood samples were collected in Vacutainer ${ }^{\circledR}$ ACD tubes (Becton-Dickinson, Rutherford, NJ, USA) prior to patient treatment. Thin blood smears were stained using a RAL $^{\circledR}$ kit (Réactifs RAL, Paris, France) based on eosin and methylene blue and were examined to determine the level of $P$. falciparum parasitemia, which ranged from 0.066 to $2.46 \%$. The evaluation of the ex vivo susceptibility to anti-malarial drugs was performed using the same venous blood samples used for diagnostic analysis.

\section{Drugs}

Chloroquine, monodesethylamodiaquine, lumefantrine, piperaquine, pyronaridine, quinine, mefloquine, dihydroartemisinin, artesunate and doxycycline were distributed into 96-well plates as previously described [7]. The batches of the plates were validated on the chloroquineresistant W2 strain (Indochina) (MR4, Virginia, USA). The clonality of this strain was regularly verified in our laboratory and by an independent laboratory from the Worldwide Antimalarial Resistance Network (WWARN) using PCR genotyping of the polymorphic genetic markers $m s p 1$ and $m s p 2$ and microsatellite loci $[8,9]$.

\section{Ex vivo assay}

The susceptibility of $P$. falciparum was evaluated using the ex vivo assay based on HRP2 ELISA as previously described [7]. The threshold values for the reduced in vitro susceptibility or resistance were the following: 61, $115,135,60,12,12,77,611,30$, and $37 \mu \mathrm{M}$ for monodesethylamodiaquine, lumefantrine, piperaquine, pyronaridine, dihydroartemisinin, artesunate, chloroquine, quinine, mefloquine and doxycycline, respectively $[4,10]$.

\section{Statistical analysis}

The $\mathrm{IC}_{50}$ values were expressed as the geometric mean of the $\mathrm{IC}_{50}$ and a confidence interval of $95 \%$ (CI 95\%) after logarithmic transformation. Cross-susceptibility was analysed using the Pearson correlation.

\section{Results}

The average parameter estimates and the prevalence of isolates with ex vivo reduced susceptibility to the ten anti-malarial drugs evaluated were shown in Table 1.

The coefficient of correlation was $0.79(\mathrm{p}<0.0001)$ for chloroquine/monodesethyamodiaquine, $0.32(\mathrm{p}=0.085)$ for chloroquine/piperaquine and 0.34 $(\mathrm{p}=0.062)$ for monodesethylamodiaquine/piperaquine.

\section{Discussion}

In the absence of the strong validation of the association between a molecular marker and resistance to the components of ACT (lumefantrine, amodiaquine, piperaquine, pyronaridine), an in vitro test is the only method currently available to provide an early indication of a change in the resistance to ACT partner drugs. Temporal surveillance of the in vitro susceptibility from the same site using identical or comparative methodology is the 
Table 1 Ex vivo susceptibility to standard anti-malarial drugs of 32 Plasmodium falciparum isolates from Dakar collected from September 2014 to November 2015. The results were compared to the P. falciparum W2 clone tested under the same conditions

\begin{tabular}{|c|c|c|c|c|}
\hline Drugs & $\begin{array}{l}\text { Isolate IC }{ }_{50} \text { mean } \\
{[\mathrm{Cl} 95 \%]}\end{array}$ & $\begin{array}{l}\text { W2 } I_{50} \text { mean } \\
{[C 195 \%]}\end{array}$ & Resistance cut-off & $\begin{array}{l}\% \text { (no) of reduced } \\
\text { susceptibility }\end{array}$ \\
\hline Monodesethylamodiaquine & $\begin{array}{l}28.9 \mathrm{nM} \\
{[21.3-39.0]}\end{array}$ & $\begin{array}{l}75 \mathrm{nM} \\
{[70-80]}\end{array}$ & $61 \mathrm{nM}$ & $28.1(9 / 32)$ \\
\hline Chloroquine & $\begin{array}{l}62.2 \mathrm{nM} \\
{[35.0-110.6]}\end{array}$ & $\begin{array}{l}324 \mathrm{nM} \\
{[199-351]}\end{array}$ & $77 \mathrm{nM}$ & $46.9(15 / 32)$ \\
\hline Lumefantrine & $\begin{array}{l}3.5 \mathrm{nM} \\
{[2.3-5.2]}\end{array}$ & $\begin{array}{l}12.4 \mathrm{nM} \\
{[9.7-18.3]}\end{array}$ & $115 \mathrm{nM}$ & $0(0 / 32)$ \\
\hline Mefloquine & $\begin{array}{l}26.0 \mathrm{nM} \\
{[18.4-36.7]}\end{array}$ & $\begin{array}{l}18.3 \mathrm{nM} \\
{[16.8-19.0]}\end{array}$ & $30 \mathrm{nM}$ & $45.2(14 / 31)$ \\
\hline Quinine & $\begin{array}{l}220.6 \mathrm{nM} \\
{[157.6-308.7]}\end{array}$ & $\begin{array}{l}294 \mathrm{nM} \\
{[277-314]}\end{array}$ & $611 \mathrm{nM}$ & $9.7(3 / 31)$ \\
\hline Piperaquine & $\begin{array}{l}36.5 \mathrm{nM} \\
{[26.5-50.4]}\end{array}$ & $\begin{array}{l}31.5 \mathrm{nM} \\
{[28.8-34.4]}\end{array}$ & $135 \mathrm{nM}$ & $0(0 / 30)$ \\
\hline Pyronaridine & $\begin{array}{l}8.7 \mathrm{nM} \\
{[5.8-13.2]}\end{array}$ & $\begin{array}{l}26.0 \mathrm{nM} \\
{[21.5-25.7]}\end{array}$ & $60 \mathrm{nM}$ & $0(0 / 30)$ \\
\hline Dihydroartemisinin & $\begin{array}{l}1.54 \mathrm{nM} \\
{[0.99-2.39]}\end{array}$ & $\begin{array}{l}1.35 \mathrm{nM} \\
{[1.14-1.60]}\end{array}$ & $12 \mathrm{nM}$ & $0(0 / 28)$ \\
\hline Artesunate & $\begin{array}{l}2.13 \mathrm{nM} \\
{[1.27-3.59]}\end{array}$ & $\begin{array}{l}1.63 \mathrm{nM} \\
{[1.41-1.92]}\end{array}$ & $12 \mathrm{nM}$ & $0(0 / 28)$ \\
\hline Doxycycline & $\begin{array}{l}25.7 \mu \mathrm{M} \\
{[19.5-33.9]}\end{array}$ & $\begin{array}{l}11.3 \mu \mathrm{M} \\
{[10.0-12.7]}\end{array}$ & $37 \mu \mathrm{M}$ & $31.2(10 / 32)$ \\
\hline
\end{tabular}

Cl 95\% confident interval 95\%

The $\mathrm{W} 2$ clone $\mathrm{IC}_{50}$ means are the results of four independent experiments

most suitable method to detect emerging and spreading resistance. Additionally, an in vitro test is the only method to assess cross-resistance between antimalarial drugs.

In the absence of standardized in vitro and ex vivo tests, the validation of the batches of plates and of a method that uses a $P$. falciparum strain (regular controls of clonality) is essential.

These in vitro and ex vivo tests were the only approach to compare results from year to year, among sites or laboratories. The in vitro effects, the $\mathrm{IC}_{50}$ values and the threshold for in vitro resistance depend on the method used. The methodology (i.e., an isotopic test versus an immunoenzymatic test), gas conditions (i.e., $\mathrm{O}_{2}$ and $\mathrm{CO}_{2}$ and the incubation time are conditions that may affect the in vitro effects and the $\mathrm{IC}_{50}$ values [11-15].

The same methodology has been used in our studies since 2013. The results for the susceptibility of the W2 clone to the different anti-malarial drugs tested during the last 6 years allow a comparison of the year over year data.

The prevalence of $P$. falciparum parasites with reduced susceptibility to monodesethylamodiaquine was $28.1 \%$ in Dakar in 2015, which confirms the increase observed in 2014 (from $5.6 \%$ in 2013 to $30.6 \%$ in 2014) ( $p=0.045$ between 2013 and 2015) [6, 7]. The geometric means were comparable in 2014 and 2015 (25.3 and $28.9 \mathrm{nM}$, respectively, $\mathrm{p}=0.517$, Welch two sample $t$ test). A three-fold increase was observed since 2013 (geometric mean, $9.8 \mathrm{nM}$ [95\% confidence interval, 5.5-17.4]) [6]. A reduced susceptibility to monodesethylamodiaquine seems to be established in Dakar since 2014. These data are consistent with previous data from Thies, which showed changes in the response to the drug amodiaquine. Specifically, the $P$. falciparum parasites became less susceptible to amodiaquine between 2008 and 2011 [16]. Susceptibility to monodesethylamodiaquine must be monitored in Senegal. Reduced susceptibility in vitro is an early warning of impeding resistance. The latest published clinical study on artesunate-amodiaquine in Senegal dated from 2012 [17]. Artesunate-amodiaquine was highly effective with an adequate clinical and parasitological response of $99.27 \%$ at day 42 .

The persistence of the increase of reduced in vitro susceptibility to monodesethylamodiaquine could be explained by the use of artesunate-amodiaquine as the treatment for uncomplicated malaria. The use of this therapy could generate the emergence of parasites resistant to amodiaquine and to monodesethylamodiaquine [18]. Secondarily, cross-resistance $(r=0.79, p<0.0001)$ between monodesethylamodiaquine and chloroquine may be the cause of the resistance or reduced 
susceptibility to both monodesethylamodiaquine and chloroquine [4, 19]. This phenomenon of cross-resistance could explain the increased in vitro resistance to chloroquine, which is no longer used in Senegal. However, an increase of chloroquine resistance was observed earlier than for monodesethylamodiaquine [6]. In fact, after a decrease of in vitro chloroquine resistance in Dakar in 2009-2011 that paralleled the withdrawal of chloroquine treatment $[4,5]$, the prevalence of parasites resistant in vitro to chloroquine increased again to approximately 50\% in Dakar since 2013 [6, 7]. The results of 2015 confirmed this increase, which nevertheless remained stable (46.9\%). This situation has not only been observed in Dakar. The in vitro susceptibility to chloroquine increased significantly between 2008 and 2011 in Thies [16] as well. Additionally, the prevalence of the mutation K76T in the $P$. falciparum chloroquine resistance transporter gene ( $p f c r t$ ) increased again to 60\% in 2006-2009 in Pikine (a suburb of Dakar) after a sharp decrease due to the cessation of chloroquine use [20].

The second ACT recommended for uncomplicated malaria treatment in Senegal is a combination of artemether-lumefantrine. In 2015, no isolate with reduced in vitro susceptibility to lumefantrine in Dakar was known. Since the introduction of ACT in Senegal, the prevalence of $P$. falciparum isolates with reduced susceptibility to lumefantrine remained low, below $3 \%$, in Dakar [4-7]. Lumefantrine did not show significant cross-resistance with the other standard anti-malarial drugs [21], and this result is consistent with clinical outcomes. All the patients in this study, who were treated by artemether-lumefantrine-doxycycline after artesunate, artesunate-doxycycline or artemether-doxycycline, were successfully cured. The artemether-lumefantrine combination was highly effective with an adequate clinical and parasitological response of $99.2 \%$ at day 42 in suburbs of Dakar in 2010-2011 and 100\% in 2012-2013 [17, 22].

The dihydroartemisinin-piperaquine combination has been recently introduced in Senegal as a second-line for the treatment of uncomplicated malaria. In 2015, no isolate with reduced in vitro susceptibility to piperaquine was observed in Dakar. The geometric means were comparable between 2013 and 2015 (32.2 nM in 2013, 34.5 in 2014 and 36.5 in 2015). Additionally, piperaquine did not show in vitro cross-resistance with chloroquine and monodesethylamodiaquine in isolates collected in Dakar $(r=0.32$, $\mathrm{p}=0.085$ and $\mathrm{r}=0.34, \mathrm{p}=0.062$, respectively). The piperaquine in vitro susceptibility was not associated with the pfcrt K76T mutation involved in chloroquine resistance [23]. The dihydroartemisinin-piperaquine combination was highly effective, with an adequate clinical and parasitological response of $99.1 \%$ at day 42 in the suburbs of Dakar in 2010-2011 and 100\% in 2012-2013 [17, 22].
Pyronaridine-artesunate, the most recent ACT, is currently under development for treatment of uncomplicated malaria. In 2015, no isolate with reduced in vitro susceptibility to pyronaridine was detected in Dakar. The geometric mean in 2015 in Dakar $(8.72 \mathrm{nM})$ was intermediate between those observed in 2013 in Dakar (5.8 nM) or in Dielmo, in southeastern Senegal, in 1996 and 1997 (3.8 and $4.5 \mathrm{nM})$ and in 2014 in Dakar (10.5 nM) [6, 7, $24,25]$. However, a decrease in pyronaridine susceptibility is feared in the future due to the association of in vitro reduced pyronaridine susceptibility with the $p f c r t \mathrm{~K} 76 \mathrm{~T}$ mutation [26]. No clinical data on artesunate-pyronaridine therapy are available from Senegal.

In 2015, no isolates with reduced in vitro susceptibility to dihydroartemisinin and to artesunate was found in Dakar. These results are consistent with those observed in previous studies in Dakar [4-6, 9]. A limitation of the present study was the absence of the determination of in vitro susceptibility to artemisinin derivatives by the ring survival test, which is a better indicator of in vitro artemisinin resistance. Clinical resistance to artemisinin was manifested by an increase in the ring-stage survival rate after contact with artemisinin [27-29].

Three P. falciparum isolates (9.7\%) showed reduced in vitro susceptibility to quinine. This prevalence is slightly above that observed in Senegal for 15 years $(2.8$ to $6 \%)[4-7,9,30]$. The two patients treated with quinine were successfully cured. Quinine is currently used less and less in Senegal in favour of intra-venous artesunate or an intra-muscular artemether injection.

Since 2009, the increase of the prevalence of parasites with reduced in vitro susceptibility to mefloquine has stabilized to approximately 50\% [4-7]. Mefloquine is rarely, if ever, used in Senegal.

Data on the in vitro susceptibility to doxycycline are disturbing. Since 2010, the prevalence of $P$. falciparum isolates with reduced susceptibility to doxycycline has gradually increased $(10.3 \%$ in 2010 and $16.7 \%$ in 2014), and it doubled in 2015 (31.2\%) [5, 7]. Additionally, the geometric mean of the doxycycline $\mathrm{IC}_{50}$ in 2015 $(25.7 \mu \mathrm{M})$ increased by a factor $2-3$ in comparison with 2009, 2010 and 2014 (9.2, 11.6 and $8.5 \mu \mathrm{M}$, respectively) $[4,5,7]$. These changes must be monitored because doxycycline is used in combination with artesunate and artemether in the Hôpital Principal of Dakar.

\section{Conclusion}

The establishment of reduced in vitro susceptibility to monodesethylamodiaquine and chloroquine resistance as well as the emergence of reduced susceptibility to doxycycline are disturbing. A limitation of this study was the low number of $P$. falciparum isolates tested. In vitro and in vivo surveillance of anti-malarial drugs 
must be implemented. The reduced in vitro susceptibility to monodesethylamodiaquine and doxycycline may quickly impact the clinical efficacy of the artemisinin combinations used in the Hôpital Principal of Dakar and in Senegal. In this context, only the artemisinin derivatives would be effective, similar to monotherapy. However, resistance of $P$. falciparum parasites to artemisinin derivatives, characterized by delayed parasite clearance after treatment with artesunate monotherapy or ACT, has recently emerged and rapidly spread in Southeast Asia, but has not had an impact up to now in Africa.

\begin{abstract}
Abbreviations
ACT: artemisinin-based combination therapy; Cl 95\%: 95\% confidence interval; ELISA: enzyme-linked immunosorbent assay; HRP2: histidine rich protein $\mathrm{II}_{\mathrm{i}} \mathrm{IC}_{50}$ : inhibitory concentration 50\%; PCR: polymerase chain reaction; Pfcrt: Plasmodium falciparum chloroquine resistance transporter gene; WWARN: Worldwide antimalarial resistance network.
\end{abstract}

\section{Authors' contributions}

$\mathrm{SD}, \mathrm{MM}, \mathrm{RA}, \mathrm{MWG}, \mathrm{BF}$ and $\mathrm{BP}$ carried out in vitro testing. SD, MBK, GL, KAW, AN, $\mathrm{RB}, \mathrm{MWG}, \mathrm{BF}$ and $\mathrm{BD}$ carried out the diagnostic tests, monitored the patients, collected clinical and epidemiological data. SD and BP conceived of and coordinated the study. MM and BP analysed the data and drafted the manuscript. All authors read and approved the final manuscript.

\begin{abstract}
Author details
${ }^{1}$ Laboratoire d'étude de la Chimiosensibilité du Paludisme, Fédération des Laboratoires, Hôpital Principal de Dakar, Dakar, Senegal. ${ }^{2}$ Unité Parasitologie et Entomologie, Département des Maladies Infectieuses, Institut de Recherche Biomédicale des Armées, Marseille, France. ${ }^{3}$ Unité de Recherche sur les Maladies Infectieuses et Tropicales Emergentes, UM 63, CNRS 7278, IRD 198, Inserm 1095, Aix Marseille Université, Marseille, France. ${ }^{4}$ Centre National de Référence du Paludisme, Marseille, France. ${ }^{5}$ Service des Urgences, Hôpital Principal de Dakar, Dakar, Senegal. ${ }^{6}$ Centre Medical Inter-armées, Dakar, Senegal. ${ }^{7}$ Laboratoire de Bactériologie Virologie, Université Cheikh Anta Diop, CHU Le Dantec, Dakar, Senegal. ${ }^{8}$ Service de Pédiatrie, Hôpital Principal de Dakar, Dakar, Senegal. ${ }^{9}$ Laboratoire d'Analyses Médicales, Institut Pasteur, Dakar, Senegal.

${ }^{10}$ Chefferie, Hôpital Principal de Dakar, Dakar, Senegal.
\end{abstract}

\section{Acknowledgements}

The authors thank the patients and the staff of the Hôpital Principal de Dakar. The authors thank Ndeye Fatou Diop and Maurice Gomis from the Hôpital Principal de Dakar for technical support.

\section{Competing interests}

The authors declare that they have no competing interests.

\section{Availability of data and material}

The datasets analysed in this study are available from the corresponding author on reasonable request.

\section{Ethics approval and consent to participate}

All the patients or their parents/guardians provided verbal consent before blood collection. Bio-banking and secondary uses of human clinical samples used for malaria diagnostics for scientific purposes are possible as long as the corresponding patients are informed and have not objected. This requirement was fulfilled in this study because oral information was given to every patient and no immediate or delayed patient opposition was reported to the hospital clinicians. The ethical committee of the Hôpital Principal de Dakar approved the study.

\section{Funding}

This study was supported by the Schéma directeur Paludisme, Etat Major des Armées Françaises (Grant LR 607a), by the Délégation Générale pour l'Armement (Grant PDH-2-NRBC-4-B-4104) and by the Ministère des Affaires Etrangères.
Received: 19 November 2016 Accepted: 10 March 2017

Published online: 16 March 2017

\section{References}

1. Mouzin E, Thior PM, Diouf MB, Sambou B. Focus on Senegal. Roll back malaria: progress and impact series. Geneva: World Health Organization; 2010. p. 1-56.

2. Dondorp AM, Nosten F, Yi P, Das D, Phyo AP, Tarning J, et al. Artemisinin resistance in Plasmodium falciparum malaria. N Engl J Med. 2009;361:455-67.

3. Ashley EA, Dhorda M, Fairhurst RM, Amaratunga C, Lim P, Suon S, et al. Spread of artemisinin resistance in Plasmodium falciparum malaria. N Engl J Med. 2015;371:411-23.

4. Fall B, Diawara S, Sow K, Baret E, Diatta B, Fall KB, et al. Ex vivo susceptibility of Plasmodium isolates from Dakar, Senegal, to seven standard antimalarial drugs. Malar J. 2011;10:310.

5. Fall B, Pascual A, Sarr FD, Wurtz N, Richard V, Baret E, et al. Plasmodium falciparum susceptibility to anti-malarial drugs in Dakar, Senegal: an ex vivo and drug resistance molecular markers study. Malar J. 2013;12:107.

6. Fall B, Camara C, Fall M, Nakoulima A, Dionne P, Diatta B, et al. Plasmodium falciparum susceptibility to standard and potential anti-malarial drugs in Dakar, Senegal, during the 2013-2014 malaria season. Malar J. 2015;14:60.

7. Fall B, Madamet M, Camara C, Amalvict R, Fall M, Nakoulima A, et al. Plasmodium falciparum in vitro resistance to monodesethylamodiaquine, Dakar, Senegal, 2014. Emerg Infect Dis. 2016;22:841-5.

8. Bogreau H, Renaud F, Bouchiba H, Durand P, Assi SB, Henry MC, et al. Genetic diversity and structure of African Plasmodium falciparum populations in urban and rural areas. Am J Trop Med Hyg. 2006;74:953-9.

9. Henry M, Diallo I, Bordes J, Ka S, Pradines B, Diatta B, et al. Urban malaria in Dakar, Senegal: chemosusceptibility and genetic diversity of Plasmodium falciparum isolates. Am J Trop Med Hyg. 2006;75:146-51.

10. Pascual A, Madamet M, Briolant S, Gaillard T, Amalvict R, Benoit N, et al. Multinormal in vitro distribution of Plasmodium falciparum susceptibility to piperaquine and pyronaridine. Malar J. 2015;14:49.

11. Pascual A, Basco LK, Baret E, Amalvict R, Travers D, Rogier C, et al. Use of the atmospheric generators for capnophilic bacteria Genbag $\mathrm{CO}_{2}^{\circledR}$ for the evaluation of in vitro Plasmodium falciparum susceptibility to standard anti-malarial drugs. Malar J. 2011;10:8.

12. Pradines B, Spiegel A, Rogier C, Tall A, Mosnier J, Fusai T, et al. Antibiotics for prophylaxis of Plasmodium falciparum infections: in vitro activity of doxycycline against Senegalese isolates. Am J Trop Med Hyg. 2000;62:82-5.

13. Pradines B, Rogier C, Fusai T, Mosnier J, Daries W, Barret E, et al. In vitro activities of antibiotics against Plasmodium falciparum are inhibited by iron. Antimicrob Agents Chemother. 2001;45:1746-50.

14. Briolant S, Parola P, Fusai T, Madamet-Torrentino M, Baret E, Mosnier J, et al. Influence of oxygen on asexual blood cycle and susceptibilily of Plasmodium falciparum to chloroquine: requirement of a standardized in vitro assay. Malar J. 2007;6:44.

15. Wein S, Maynadier M, Tran Van Ba C, Cerdan R, Peyrottes S, Fraisse L, et al. Reliability of antimalarial sensitivity tests depends on drug mechanism of action. J Clin Microbiol. 2010;48:1651-60.

16. Van Tyne D, Dieye B, Valim C, Daniels RF, Sène PD, Lukens AK, et al. Changes in drug sensitivity and anti-malarial drug resistance mutations over time among Plasmodium falciparum parasites in Senegal. Malar J. 2013;12:441.

17. Sylla K, Abiola A, Tine RC, Faye B, Sow D, Ndiaye JL, et al. Monitoring the efficacy and safety of three artemisinin based-combinations therapies in Senegal: results from two years surveillance. BMC Infect Dis. 2013;13:598.

18. Thiam S, Thior M, Faye B, Ndiop M, Diouf ML, Diouf MB, et al. Major reduction in antimalarial drug consumption in Senegal after nation-wide introduction of malaria rapid diagnostic tests. PLoS ONE. 2011;6:4.

19. Pradines B, Mabika Mamfoumbi M, Parzy D, Owono Medang M, Lebeau C, Mourou Mbina JR, et al. In vitro susceptibility of African ioslates of Plasmodium falciparum from Gabon to pyronaridine. Am J Trop Med Hyg. 1999;60:105-8.

20. Ly O, Gueye PE, Deme AB, Dieng T, Badiane AS, Ahouidi AD, et al. Evolution of the pfcrt T76 and pfmdr 1 Y 86 markers and chloroquine susceptibility 8 years after cessation of chloroquine use in Pikine. Senegal. Parasitol Res. 2012:111:1541-6. 
21. Pradines B, Tall A, Fusai T, Spiegel A, Hienne R, Rogier C, et al. In vitro activities of benflumetol against 158 Senegalese isolates of Plasmodium falciparum in comparison with those of standard antimalarial drugs. Antimicrob Agents Chemother. 1999;43:418-20.

22. Sow D, Ndiaye JL, Sylla K, Ba MS, Tine RC, Faye B, et al. Evaluation of the efficacy and safety of three 2-drug combinations for the treatment of uncomplicated Plasmodium falciparum malaria in Senegal: artesunateamodiaquine, dihydroartemisinin-piperaquine, and artemether-lumefantrine. Med Sante Trop. 2016;26:45-50.

23. Pascual A, Madamet M, Bertaux L, Amalvict R, Benoit N, Travers D, et al. In vitro piperaquine susceptibility is not associated with the Plasmodium falciparum chloroquine resistance transporter gene. Malar J. 2013;12:431.

24. Pradines B, Tall A, Parzy D, Spiegel A, Fusai T, Hienne R, et al. In vitro activity of pyronaridine and amodiaquine against African isolates (Senegal) of Plasmodium falciparum in comparison with standard antimalarial agents. J Antimicrob Chemother. 1998:42:333-9.

25. Pradines B, Tall A, Ramiandrasoa F, Spiegel A, Sokhna C, Fusai T, et al. In vitro activity of iron-binding compounds against Senegalese isolates of Plasmodium falciparum. J Antimicrob Chemother. 2006;57:1093-9.
26. Madamet M, Briolant S, Amalvict R, Benoit N, Bouchiba H, Cren J, et al. The Plasmodium falciparum chloroquine resistance transporter is associated with the ex vivo $P$. falciparum African parasite response to pyronaridine. Parasit Vectors. 2016;9:77.

27. Witkowski B, Amaratunga C, Khim N, Sreng S, Chim P, Kim S, et al. Novel phenotypic assays for the detection of artemisinin-resistant Plasmodium falciparum malaria in Cambodia: in vitro and ex vivo drug-response studies. Lancet Infect Dis. 2013;13:1043-9.

28. Ariey F, Witkowsky B, Amaratunga C, Beghain J, Langlois AC, Khim N, et al. A molecular marker of artemisinin-resistant Plasmodium falciparum malaria. Nature. 2014;505:50-5.

29. Amaratunga C, Witkowski B, Khim N, Menard D, Fairhurst RM. Artemisinin resistance in Plasmodium falciparum. Lancet Infect Dis. 2014;14:449-50.

30. Jambou R, Legrand E, Niang M, Khim N, Lim P, Volney B, et al. Resistance of Plasmodium falciparum field isolates to in vitro artemether and point mutations of the SERCA-type PfATPase6. Lancet. 2005;366:1960-3.

\section{Submit your next manuscript to BioMed Central and we will help you at every step:}

- We accept pre-submission inquiries

- Our selector tool helps you to find the most relevant journal

- We provide round the clock customer support

- Convenient online submission

- Thorough peer review

- Inclusion in PubMed and all major indexing services

- Maximum visibility for your research

Submit your manuscript at www.biomedcentral.com/submit
() Biomed Central 